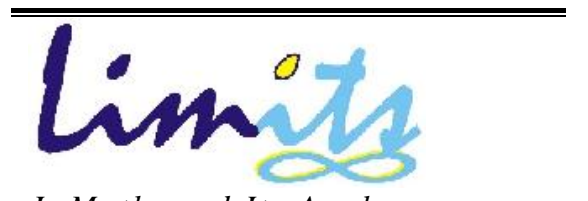

J. Math. and Its Appl.

ISSN: $1829-605 \mathrm{X}$

Vol. 13, No. 1, Mei 2016, 1-10

\title{
ANALISIS MODEL LINTASAN NANOPARTIKEL MAGNET PADA PEMBULUH DARAH DI DALAM MEDAN MAGNET DENGAN METODE RUNGE KUTTA ORDE KE-EMPAT
}

\author{
Tahiyatul Asfihani ${ }^{1}$, Hesti Hastuti ${ }^{2}$, Chairul Imron ${ }^{3}$ \\ 1,2,3 Jurusan Matematika, Fakultas Matematika dan Ilmu Pengetahuan Alam, \\ Institut Teknologi Sepuluh Nopember (ITS) \\ Jl. Arief Rahman Hakim, Surabaya 60111 Indonesia \\ t_asfihani@matematika.its.ac.id, hesti.hastuti.its@gmail.com, imron- \\ its@matematika.its.ac.id
}

\begin{abstract}
Abstrak
Nanopartikel magnetik memiliki peran penting dalam dunia kedokteran modern yaitu sebagai obat yang ditargetkan oleh magnet. Obat yang ditargetkan oleh magnet tersebut disuntikan kedalam tubuh kemudian akan dibawa oleh darah mengalir ke seluruh tubuh. Untuk memperoleh hasil yang lebih optimal, diperlukan suatu model lintasan nanopartikel magnet didalam embuluh darah. Sistem tersebut dibantu dengan medan magnet yang diposisikan diluar tubuh. Dengan menggunakan metode Runge-kutta, diperoleh jarak antara pusat pembuluh darah dengan pusat medan magnet yang lebih tepat adalah $0.025 \mathrm{~m}$ dimana posisi lintasannya menuju kearah pusat medan magnet yaitu nol $(\mathrm{z} / \mathrm{Rm}=0)$.

Kata Kunci: Nanopartikel magnetik, Obat yang ditargetkan oleh magnet, Lintasan nanopartikel magnetik, Metode Runge Kutta
\end{abstract}

\section{Pendahuluan}

Nanoteknologi merupakan teknologi yang memungkinkan sebuah benda dipecah dalam skala nanometer atau satu per semiliar meter yang mampu mendorong pertumbuhan industri dan ekonomi di segala bidang. Salah satunya adalah nanopartikel magnetik yang telah dipelajari dan diaplikasikan secara luas dalam bidang biomedis. Nanopartikel magnetik ini merupakan suatu partikel dengan ukuran nanometer yaitu sekitar 1-100nm. Hal ini akan menyebabkan nanopartikel dalam proses ekstraksinya mudah larut dan memiliki efisiensi penyerapan yang tinggi di usus sehingga nanopartikel memiliki peran penting dalam dunia 
kedokteran modern. Dengan sistem aplikasi klinis, nanopartikel tersebut digunakan sebagai agen kontras dalam pencitraan untuk obat-obatan dan pembawa gen yang dikirimkan ke tumor. Salah satunya yang sering digunakan adalah nanopartikel jenis besi oksida $[1,2,3]$.

Agar memperoleh hasil yang optimal dalam proses penargetan obat magnet, maka perlu dilakukan suatu model matematik untuk menentukan posisi lintasan nanopartikel magnet di dalam pembuluh darah dengan bantuan medan magnet yang diposisikan diluar tubuh tersebut. Kemudian hasil dari model matematik tersebut, akan diselesaikan secara numerik dengan menggunakan metode runge kutta orde ke-4.

\section{1 Gerak Nanopartikel Magnet di dalam Pembuluh Darah}

Nanopartikel ini sangat penting dalam proses pengantar obat secara intravena sehingga dapat melewati pembuluh darah terkecil secara aman. Ketika partikel magnetik yang memiliki suspensi homogen disuntikan pada penderita menuju daerah penargetan magnet didalam pembuluh darah. Partikel-partikel homogen tersebut secara bersamaan mengalami gaya magnet, gaya fluida dan gaya apung akibat dari gaya gravitasi seperti pada Gambar $1 \mathrm{di}$ bawah ini [4]:

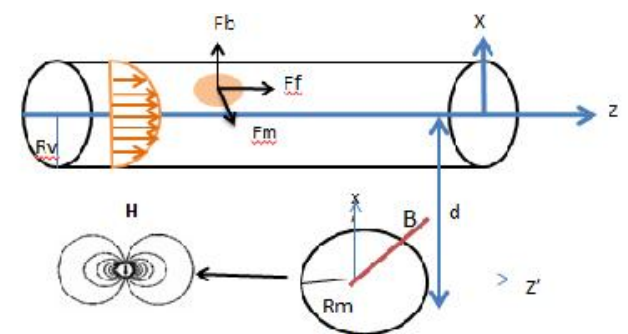

Gambar 1. Nanopartikel magnet didalam pembuluh darah dengan bantuan medan magnet yang diposisikan diluar tubuh

Berdasarkan hukum Newton kedua gaya yang terjadi pada nanopartikel magnet adalah sebagai berikut:

$$
m_{p} \frac{d V_{p}}{d}=\sum F_{e}
$$

Karena hasil dari $m_{p} \frac{d V_{p}}{d}$ sangat kecil dan mendekati nol maka persamaan menjadi :

$$
\sum F_{e}=0
$$

$$
\sum F_{e}=F_{m}+F_{I}+F_{b}
$$

Jika partikel magnetik tersuspensi dalam cairan dengan permeabilitas $\mu_{U}$, gaya yang dialami oleh partikel magnetik dalam medan magnet $\mathrm{H}$ adalah gaya magnetik dengan perhitungan sebagai berikut:

$$
\overrightarrow{F_{m}}=\mu_{u} V_{H^{\prime}} \frac{X_{p}}{\left(3+X_{p}\right)}(\nabla \cdot H) \vec{H}
$$

dimana $X_{p}$ adalah kerentangan magnetik pada partikel yang bertipe ferromagnetik dan $\mu_{U}$ adalah permiabilitas ruang hampa dengan besarnya $4 \pi \times 10^{-2} N / A^{2}$. Besarnya gaya magnet pada partikel ferromagnetik selalu dari rendah ke medan magnet yang lebih tinggi dan sebanding dengan gradient intensitas medan magnet kuadrat. Sedangkan nanopartikel magnet yang bergerak di dalam pembuluh darah dengan aliran darah laminar akan menghasilkan gaya stokes yaitu gaya gesek yang terjadi pada benda yang bergerak dengan jari-jari $R_{p}$ dalam aliran seragam, dimana $\eta$ dan $v_{f}$ adalah viskositas dan kecepatan fluida, dan $v_{P}$ adalah kecepatan partake dan dirumuskan dengan persamaan berikut:

$$
\begin{aligned}
& F_{f}=k \\
& F_{f}=k\left(v_{p}-v_{f}\right)
\end{aligned}
$$

dimana $k=6 \pi K_{p}$ adalah koefisien viskositas, maka :

$$
F_{f}=6 \pi R_{p}\left(v_{P}-v_{f}\right)
$$


Jika diasumsikan bahwa pembuluh darah berbentuk silinder dan aliran darah adalah aliran laminar parallel.

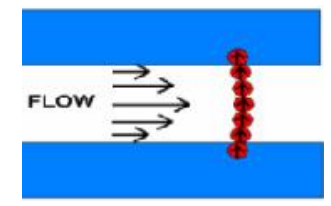

Gambar 2. Aliran laminar pada pembuluh darah untuk itu, kecepatan fluida dapat dirumuskan sebagai berikut:

$$
v_{T}(x)=2 \overline{v_{J}}\left[1-\left(\frac{x}{K_{v}}\right)^{2}\right]
$$

Gaya apung yang terjadi pada partikel tersebut dipengaruhi oleh gaya gravitasi didalam viskositas fluida. Besarnya gaya tersebut dapat dihitung dengan menggunakan rumus sebagai berikut:

$$
\begin{gathered}
F_{b}=V_{p} \rho \hat{x} \\
F_{b}=V_{p}\left(\rho_{f}-\rho_{p}\right) g \hat{x}
\end{gathered}
$$

dengan $\rho_{p}$ dan $\rho_{f}$ adalah massa jenis partikel dan fluida serta diketahui bahwa percepatan gravitasi $g=9.8 \mathrm{~m} / \mathrm{s}$. Gaya apung hanya terjadi terhadap sumbu $x$ karena dipengaruhi oleh gaya gravitasi bumi, sementara terhadap sumbu $z$ besar gayanya adalah nol.

\section{2 Gerak Kecepatan Partikel}

Berdasarkan hasil perhitungan gaya yang bekerja pada nanopartikel magnet yang dilakukan oleh Shasi Sharma dkk diperoleh Komponen kecepatan dari partikel magnet terhadap sumbu $\mathrm{x}$ dan $\mathrm{z}$ dengan perhitungan sebagai berikut[2] :

dan

$$
v_{p, x}=\frac{1}{3 \eta} \mu_{0} K_{p}^{2} M_{s}^{2} K_{m}^{4} \frac{d}{\left(d^{2}+z^{2}\right)^{3}}-\frac{2}{9 \eta} K_{p}^{2}\left(\rho_{p}-\rho_{f}\right) g
$$

$$
\nu_{p, \mathrm{Z}}=\frac{1}{3 \eta} \mu_{0} K_{p}^{2} M_{s}^{2} K_{m}^{4} \frac{z}{\left(d^{2}+z^{2}\right)^{3}}-2 \overline{V_{J}}\left\lfloor 1-\left(\frac{x}{K_{\nu}}\right)^{2}\right\rfloor
$$

\section{Hasil dan Pembahasan}

\subsection{Model Lintasan Nanopartikel Magnet didalam Pembuluh Darah dengan Bantuan Medan Magnet diluar Tubuh}

Berdasarkan (1) lintasan nanopartikel magnet terhadap hukum Newton 1 adalah:

$$
\sum F_{e}=F_{m}+F_{f}+F_{b}=0
$$

dimana $F_{m}$ merupakan gaya magnet akibat dari medan magnet yang diposisikan diluar tubuh. Dengan menggunakan persamaan Maxwell maka diperoleh gaya magnet seperti pada persamaan dibawah ini [5]:

$$
\overrightarrow{F_{m}}=2 K_{p} C \quad(\nabla \cdot \vec{H}) \vec{H}
$$

dengan $K_{p}=2 \pi K_{p}$ adalah keliling partikel dan $c=\frac{K_{p}^{2}}{\varphi_{\eta}} \frac{\mu_{0} X_{p}}{1+\frac{x_{p}}{g}}$ adalah koefisien hanyut magnetik pada nanopartikel jenis ferromagnetik[4]. Sehingga persamaan gaya magnet yang diperoleh adalah seperti pada persamaan dibawah ini:

Sesuai dengan (2) maka:

$$
\begin{aligned}
& \overrightarrow{F_{m}}=2.2 \pi K_{p}\left(\frac{K_{p}^{2}}{9 \eta} \frac{\mu_{0} X_{p}}{1+\frac{X_{p}}{3}}\right) \eta(\nabla \cdot \vec{H}) \vec{H} \\
& \overrightarrow{F_{m}}=4 \pi R_{p}\left(\frac{K_{p}^{2}}{9 \eta} \frac{3 \mu_{0} X_{p}}{\left(3+X_{p}\right)}\right) \eta(\nabla \cdot \vec{H}) \vec{H} \\
& \overrightarrow{F_{m}}=\frac{4 \pi K_{p}^{3}}{3} \frac{\mu_{0} X_{p}}{\left(3+X_{p}\right)}(\nabla \cdot \vec{H}) \vec{H}
\end{aligned}
$$

$$
\overrightarrow{F_{m}}=\mu_{0} V_{P} \frac{X_{p}}{\left(3+X_{p}\right)}(\nabla \cdot \vec{H}) \vec{H}
$$


dengan $H(x, z)=H_{x}(x, z) \vec{x}+H_{z}(x, z) \vec{z}$ yaitu medan magnet dengan komponen arah sumbu $x$ dan arah sumbu $z$. Akibatnya total gaya magnet yang terjadi pada nanopartikel pembawa magnet tersebut menjadi:

$$
\begin{aligned}
& F_{m} \vec{x}=F_{m}(x, z) \quad F_{m}=F_{m} \vec{x}+F_{m} \vec{z} \\
& =\mu_{0} V_{p} \frac{\exists x_{p}}{x_{p}+3}\left[H_{x}(x, z) \frac{\partial H_{x}(x, z)}{\partial}+H_{z}(x, z) \frac{\partial H_{x}(x, z)}{\partial}\right] \\
& F_{m} \vec{z}=F_{m}(x, z) \\
& =\mu_{0} V_{p} \frac{3 x_{p}}{x_{p}+3}\left[H_{x}(x, z) \frac{\partial H_{z}(x, z)}{\partial}+H_{z}(x, z) \frac{\partial H_{z}(x, z)}{\partial}\right]
\end{aligned}
$$

Sedangkan medan magnet pada silinder magnet yang tidak terbatas dan tegak lurus terhadap sumbu-sumbunya dapat dirumuskan sebagai berikut:

$$
\begin{aligned}
& H_{x}(x, z)=\frac{M_{S} K_{m}^{2}\left[(x+d)^{2}-z^{2}\right]}{2\left[(x+d)^{2}+z^{2}\right]^{2}} \\
& H_{z}(x, z)=\frac{M_{S} K_{m}^{2} z(x+d) z}{2\left[(x+d)^{2}+z^{2}\right]^{2}}
\end{aligned}
$$

dan diperoleh turunan parsial dari medan magnet terhadap sumbu $x$ dan $\mathrm{z}$ seperti pada persamaan dibawah ini:

$$
\begin{aligned}
& \frac{\partial H_{x}(x, z)}{\partial}=\frac{M_{\mathrm{s}} R_{m}^{2}}{2} \\
& \left(\frac{2(x+d)\left[(x+d)^{2}+z^{2}\right]^{2}-\left[(x+d)^{2}-z^{2}\right] 2\left[(x+d)^{2}+z^{2}\right] 2(x+d)}{\left[(x+d)^{2}+z^{2}\right]^{4}}\right) \\
& \frac{\partial H_{x}(x, z)}{\partial}=-M_{\mathrm{s}} K_{m}^{2} \frac{(x+d)\left[(x+d)^{2}-3 z^{2}\right]}{\left[(x+d)^{2}+z^{2}\right]^{3}} \\
& \frac{\partial H_{x}(x, z)}{\partial}=\frac{M_{\mathrm{s}} K_{m}^{2}}{2} \\
& \left(\frac{-2 z\left[(x+d)^{2}+z^{2}\right]^{2}-\left[(x+d)^{2}-z^{2}\right] 2\left[(x+d)^{2}+z^{2}\right] 2 z}{\left[(x+d)^{2}+z^{2}\right]^{4}}\right) \\
& \frac{\partial H_{x}(x, z)}{\partial}=-M_{\mathrm{s}} K_{m}^{2} \frac{z\left[3(x+d)^{2}-z^{2}\right]}{\left[(x+d)^{2}+z^{2}\right]^{3}} \\
& \frac{\partial H_{z}(x, z)}{\partial}=M_{s} K_{m}^{2} \\
& \left(\frac{z\left[(x+d)^{2}+z^{2}\right]^{2}-(x+d) z 2\left[(x+d)^{2}+z^{2}\right] 2(x+d)}{\left[(x+d)^{2}+z^{2}\right]^{4}}\right) \\
& \frac{\partial H_{z}(x, z)}{\partial}=M_{S} K_{m}^{L} \frac{z\left[z^{2}-3(x+d)^{2}\right]}{\left[(x+d)^{2}+z^{2}\right]^{2}} \\
& \frac{\partial H_{L}(x, z)}{\partial}=M_{\mathrm{S}} K_{m}^{2} \\
& \left(\frac{(x+d)\left[(x+d)^{2}+z^{2}\right]^{2}-(x+d) z 2\left[(x+d)^{2}+z^{2}\right] 2 z}{\left[(x+d)^{2}+z^{2}\right]^{4}}\right) \\
& \frac{\partial H_{z}(x, z)}{\partial}=M_{s} R_{m}^{2} \frac{(x+d)\left[(x+d)^{2}-3 z^{2}\right.}{\left[(x+d)^{2}+z^{2}\right]^{3}}
\end{aligned}
$$

Dengan menggunakan (12), (13) dan (14) maka (10) dan (11) menjadi:

$$
\begin{gathered}
F_{m}(x, z)=\mu_{0} V_{p} \frac{3 x_{p}}{x_{p}+3} \\
{\left[\left(\frac{M_{s} K_{m}^{2}\left[(x+d)^{2}-z^{2}\right]}{2\left[(x+d)^{2}+z^{2}\right]^{2}}\right)\left(-M_{\mathrm{s}} K_{m}^{2} \frac{(x+d)\left[(x+d)^{2}-3 z^{2}\right]}{\left[(x+d)^{2}+z^{2}\right]^{3}}\right)\right.} \\
\left.+\left(\frac{M_{\mathrm{s}} K_{m}^{2} 2(x+d) z}{2\left[(x+d)^{2}+z^{2}\right]^{2}}\right)\left(-M_{\mathrm{s}} R_{m}^{2} \frac{z\left[3(x+d)^{2}-z^{2}\right]}{\left[(x+d)^{2}+z^{2}\right]^{3}}\right)\right] \\
F_{m}(x, z)=\mu_{\mathrm{u}} V_{p} \frac{3 x_{p}}{x_{p}+3} \\
{\left[\left(\frac{M_{\mathrm{s}} R_{m}^{2}\left[(x+d)^{2}-z^{2}\right]}{2\left[(x+d)^{2}+z^{2}\right]^{2}}\right)\left(M_{\mathrm{s}} R_{m}^{2} \frac{z\left[z^{2}-3(x+d)^{2}\right]}{\left[(x+d)^{2}+z^{2}\right]^{3}}\right)\right.} \\
\left.+\left(\frac{M_{s} K_{m}^{2} 2(x+d) z}{2\left[(x+d)^{2}+z^{2}\right]^{2}}\right)\left(M_{\mathrm{s}} R_{m}^{2} \frac{(x+d)\left[(x+d)^{2}-3 z^{2}\right]}{\left[(x+d)^{2}+z^{2}\right]^{3}}\right)\right]
\end{gathered}
$$

Misal $(x+d)=p$, maka :

$$
F_{m}(x, z)=-\mu_{0} V_{p} M_{\mathrm{s}}{ }^{2} K_{m}^{4} \frac{3 x_{p}}{x_{p}+3}\left(\frac{p}{2\left(p^{2}+z^{2}\right)^{4}}\right)
$$




$$
F_{m}(x, z)=-\mu_{\mathrm{u}} V_{p} M_{\mathrm{s}}^{2} K_{m}^{4} \frac{3 x_{p}}{x_{p}+3}\left(\frac{z}{2\left(p^{2}+z^{2}\right)^{4}}\right)
$$

Diketahui bahwa nanopartikel jenis ferromagnetic ini memiliki $x_{p} \gg 1$ artinya suspensinya sangat besar sehingga $x_{p}+3 \geq x_{p}$. Dan nilai dari $\frac{x}{d} \ll 1$ artinya nilai $\mathrm{x}$ sangat kecil sehingga $x \approx 0$. untuk itu, (15) dan (16) menjadi:

$$
\begin{aligned}
& F_{m}(x, z)=-3 \mu_{0} V_{p} M_{\mathrm{s}}{ }^{2} K_{m}^{4}\left(\frac{d}{2\left(d^{2}+z^{2}\right)^{4}}\right) \\
& F_{m}(x, z)=-3 \mu_{v} V_{p} M_{\mathrm{s}}{ }^{2} K_{m}^{4}\left(\frac{\mathrm{z}}{2\left(d^{2}+z^{2}\right)^{4}}\right)
\end{aligned}
$$

Berdasarkan (3) dan (4), gaya fluida juga dipengaruhi oleh arah sumbu $x$ dan sumbu $z$ sehingga:

$$
\begin{gathered}
F_{f}=F_{f} \vec{x}+F_{f} \vec{z} \\
F_{f}=6 \pi \quad R_{p} v_{P, x} \\
F_{f}=6 \pi \quad K_{p}\left(v_{P, z}-v_{f, x}\right) \\
F_{f}=6 \pi \quad K_{p}\left(v_{P, z}-2 \overline{v_{f}}\left[1-\left(\frac{x}{K_{v}}\right)^{2}\right]\right)
\end{gathered}
$$

Berdasarkan (1), (5), (17), (18), (19) dan (20) maka kecepatan partikel terhadap sumbu $x$ :

$$
\begin{aligned}
& \begin{array}{c}
F_{m}+F_{I}+F_{b}=0 \\
-3 \mu_{0} V_{p} M_{\mathrm{s}}{ }^{2} K_{m}^{4}\left(\frac{d}{2\left(d^{2}+z^{2}\right)^{3}}\right)+6 \pi k_{p} v_{\mu, x}+V_{p}\left(\rho_{p}-\rho_{f}\right) g=0
\end{array} \\
& 6 \pi K_{p} v_{\mu, x}=3 \mu_{0} V_{p} M_{\mathrm{s}}{ }^{2} K_{m}^{4}\left(\frac{d}{2\left(d^{2}+z^{2}\right)^{3}}\right)-V_{p}\left(\rho_{p}-\rho_{f}\right) g \\
& v_{p, x}=3 \mu_{0} \frac{4 \pi K_{p}{ }^{3}}{18 \pi K_{p}} M_{s}{ }^{2} K_{m}^{4}\left(\frac{d}{2\left(d^{2}+z^{2}\right)^{3}}\right)-\frac{4 \pi K_{p}{ }^{3}}{18 \pi K_{p}}\left(\rho_{p}-\rho_{f}\right) g \\
& v_{\mu, x}=\frac{d}{d}=\mu_{0} \frac{M_{s}{ }^{2} K_{m}^{4} K_{p}{ }^{2}}{3 r_{l}}\left(\frac{d}{\left(d^{2}+z^{2}\right)^{3}}\right)-\frac{2 K_{p}^{2}}{9 r_{l}}\left(\rho_{p}-\rho_{f}\right) g
\end{aligned}
$$

Sedangkan terhadap sumbu $z$ diperoleh keccepatan partikel sebagai berikut:

$$
\begin{aligned}
& F_{m}+F_{f}+F_{b}=0 \\
& F_{b}=0 \\
& -3 \mu_{\mathrm{v}} V_{p} M_{\mathrm{s}}{ }^{2} R_{m}^{4}\left(\frac{z}{2\left(d^{2}+z^{2}\right)^{3}}\right)+6 \pi R_{p}\left(v_{t, z}-2 \overline{v_{f}}\left[1-\left(\frac{x}{k_{v}}\right)^{2}\right]\right)=0 \\
& 6 \pi R_{p} v_{r, z}=3 \mu_{\mathrm{u}} V_{p} M_{\mathrm{s}}{ }^{2} R_{m}^{4}\left(\left(\frac{z}{2\left(d^{2}+z^{2}\right)^{3}}\right)+12 \overline{\nabla_{f}} \pi R_{p}\left[1-\left(\frac{x}{R_{v}}\right)^{2}\right]\right) \\
& V_{r, Z}=3 \mu_{\mathrm{L}} \frac{4 \pi R_{F}{ }^{3}}{18 \pi R_{F}} M_{s}{ }^{2} R_{m}^{4}\left(\left(\frac{z}{2\left(d^{2}+z^{2}\right)^{3}}\right)+\frac{12 \overline{V_{f}} \pi R_{F}}{6 \pi R_{p}}\left[1-\left(\frac{x}{R_{v}}\right)^{2}\right]\right) \\
& \left.v_{\psi, z}=\frac{d}{d}=\mu_{0} \frac{M_{s}{ }^{2} K_{m}^{4} K_{p}{ }^{2}}{3 r_{l}} M_{\mathrm{s}}{ }^{2} K_{m}^{4}\left(\frac{\mathrm{z}}{\left(d^{2}+z^{2}\right)^{3}}\right)+2 \overline{v_{I}}\left[1-\left(\frac{x}{K_{v}}\right)^{2}\right\rfloor\right)
\end{aligned}
$$

\subsection{Penyelesaian Numerik Model Lintasan Nanopartikel Magnet di dalam Pembuluh Darah}

Penyelesaian numerik yang digunakan adalah metode Runge-Kutta orde ke- empat. Metode ini mempunyai suatu galat pemotongan $h^{4}$. Integrasi numerik dari persamaan dengan menggunakan metode Runge-Kutta orde empat dinyatakan sebagai berikut:

$$
\begin{aligned}
& x_{n+1}=x_{n}+\frac{1}{6}\left(k_{1, x}+2 k_{2, x}+2 k_{3, x}+k_{4, x}\right), \quad z_{n+1}=z_{n}+\frac{1}{6}\left(k_{1, z}+2 k_{2, z}+2 k_{3, z}+k_{4, z}\right) \\
& k_{1, x}=h v_{P, x}\left(t_{U}, x_{U}, z_{U}\right), k_{1, z}=h v_{P, z}\left(t_{U}, x_{U}, z_{U}\right) \\
& k_{2, x}=h v_{P, x}\left(t_{U}+\frac{h}{2}, x_{U}+\frac{k_{1, x}}{2}, z_{U}+\frac{k_{1, z}}{2}\right), k_{2, z}=h v_{P, z}\left(t_{U}+\frac{h}{2}, x_{U}+\frac{k_{1, x}}{2}, z_{U}+\frac{k_{1, z}}{2}\right) \\
& k_{3, x}=h v_{P, x}\left(t_{U}+\frac{h}{2}, x_{U}+\frac{k_{L, x}}{2}, z_{U}+\frac{k_{L, 2}}{2}\right), k_{3, \mathrm{~L}}=h v_{P, \mathrm{Z}}\left(t_{0}+\frac{h}{2}, x_{0}+\frac{k_{2, \mathrm{x}}}{2}, z_{0}+\frac{k_{2, \mathrm{~L}}}{2}\right) \\
& k_{4, x}=h v_{P, x}\left(t_{0}+\frac{h}{2}, x_{0}+\frac{k_{3, x}}{2}, z_{0}+\frac{k_{3, \bar{L}}}{2}\right), k_{4, \mathrm{~L}}=h v_{P, z}\left(t_{0}+\frac{h}{2}, x_{0}+\frac{k_{3, x}}{2}, z_{0}+\frac{k_{3, \bar{L}}}{2}\right)
\end{aligned}
$$

\subsection{Simulasi}

Partikel yang berjenis ferromagnetik ini (Fe3O4) memiliki jari-jari $\left(K_{p}=300 n\right)$ di dalamnya serta mengandung nanopartikel magnetik dengan massa jenis $\rho_{p}=5000 \mathrm{k} / \mathrm{m}^{3}$ 
yang akan ditransportasikan kedalam pembuluh darah dengan medan magnet. Diasumsikan bahwa suspensibilitas magnet dari partikel Fe3O4 sangat luas dalam perbandingan $\left(x_{p} \gg 1\right)$. Dengan dipasangkan magnet berbentuk silinder yang diposisikan diluar tubuh yang berdiameter $4 \mathrm{~cm}\left(K_{m}=2\right)$ dan besarnya magnetisasi $\left(M_{\mathrm{s}}=10^{6} \mathrm{~A} / \mathrm{m}\right)$. Jari-jari dari pembuluh darah $\left(K_{v}=75 \mu\right.$ dan rata-rata kecepatan aliran $\left(v_{f}=10 \mathrm{~m} / \mathrm{s}\right)$. Dengan viskositas $(\eta)$ dan massa jenis $\left(\rho_{f}\right)$ dari darah diasumsikan $3,2 \times 10^{-3} \mathrm{~N} \mathrm{~s} / \mathrm{m}^{2}$ dan $1060 \mathrm{k} / \mathrm{m}^{3}$ serta waktu yang dibutuhkan 130 detik maka hasil simulasi menggunakan metode Runge-Kutta dengan software Matlab akan menghasilkan gambar seperti dibawah ini :

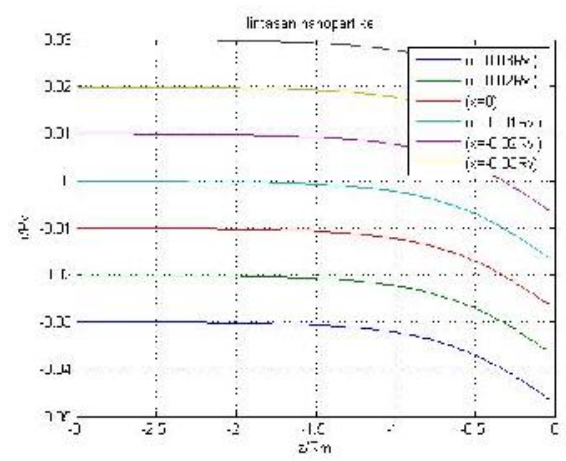

Gambar 3. Lintasan nanopartikel didalam pembuluh darah dengan posisi yang bervariasi untuk $\mathrm{d}=2,5 \mathrm{~cm}$

Analisis dari gambar 3 adalah lintasan nanopartikel magnet yang mengalir didalam pembuluh darah dengan menggunakan persamaan (21) dan (22) dan posisi partikel bervariasi $x=-0.03 k,-0.02 K,-0.01 K, 0,0.01 K, 0.02 K, 0.03 k$ Berdasarkan gambar tersebut dapat diamati bahwa semua partikel bergerak menuju ke pusat medan magnet $(z / R=0)$ dengan waktu yang bersamaan dan posisi awal yang sama

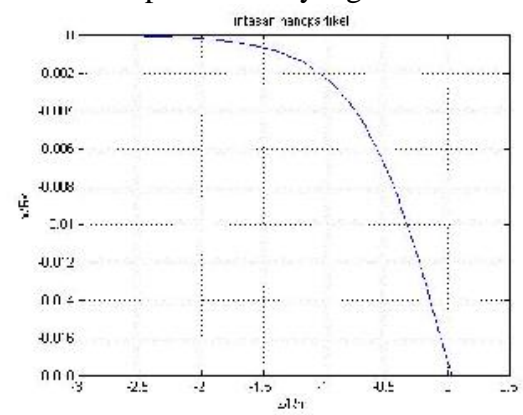

Gambar 4. Lintasan nanopartikel didalam pembuluh darah dengan posisi $x=0$ dan

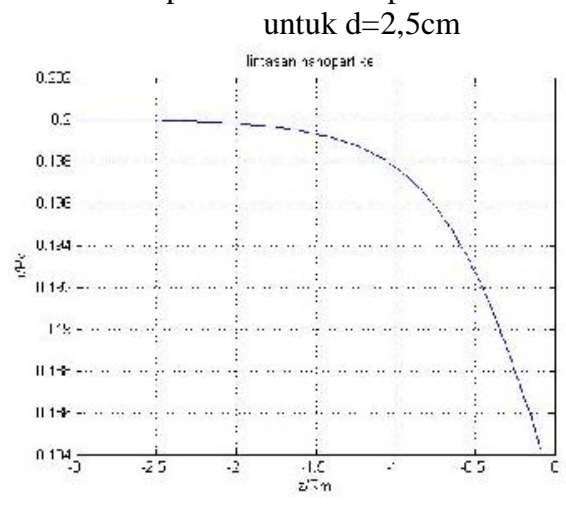

Gambar 5. Lintasan nanopartikel didalam pembuluh darah dengan posisi $x$ $=0.2 \mathrm{Rv}$ dan untuk $\mathrm{d}=2,5 \mathrm{~cm}$ 


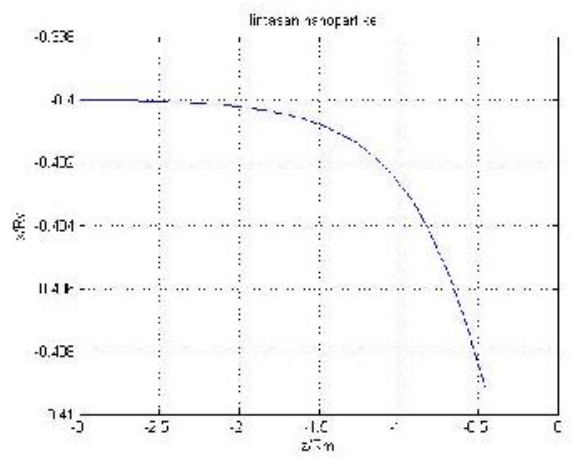

Gambar 6. Lintasan nanopartikel didalam pembuluh darah dengan $x=-0.4$ dan untuk $\mathrm{d}=2,5 \mathrm{~cm}$.

Analisis pada gambar 4,5,6 menunjukan hal yang sama dengan gambar 3 bahwa setiap partikel bergerak menuju ke pusat medan magnet $(z / K=0)$ misalnya $x=0, x=0.2 R, x=$ $-0.4 K$

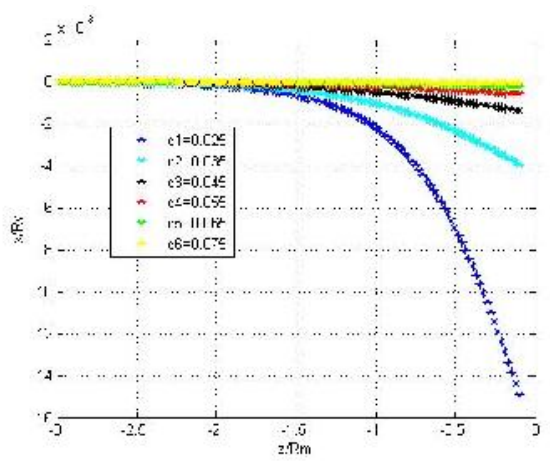

Gambar 7. Lintasan nanopartikel dengan d (pusat magnet dengan pusat pembuluh darah yang berbeda)

Analisis dari Gambar 7 terdapat perbedaan pada lintasan nanopartikelnya jika jarak pusat magnet dengan pusat pembuluh darah dibuat bervariasi. Lintasan yang paling tepat adalah lintasan yang memiliki jarak $0.025 \mathrm{~m}$ yaitu mendekati pusat medan magnet $(z / K=0)$.

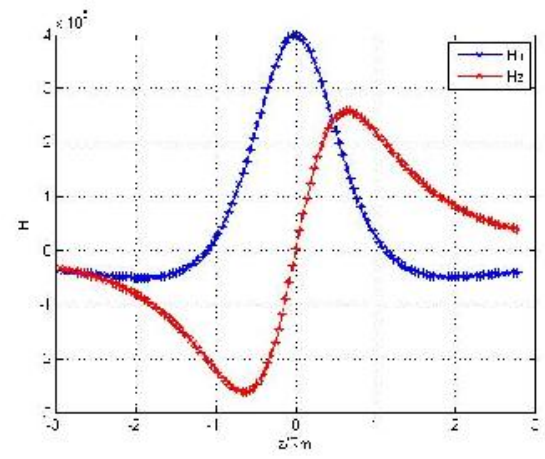

Gambar 8. Komponen medan magnet $\left(\begin{array}{lll}H & d & H\end{array}\right)$ terhadap pusat pembuluh darah. Analisis pada Gambar 8 membuktikan bahwa komponenmedan magnet terhadap pembuluh darah (-3R $\leq z \leq \leq 3 R$ ) dengan menggunakan (12) dan (13) untuk $d=0.025$ $m$ terbukti bahwa nilai maksimal pada komponen $H=4.10^{5} \mathrm{M}=4000 \mathrm{~g} \mathrm{~s}$ terhadap pusatmagnet $(z / R=0)$. Sedangkan $H$ beroksilasi didaerahpusat pembuluh darah dan menunjukan puncak menuju ke tepmagnet $(z / R= \pm 1)$ itu yang berubah arahnya dari satu sisi ke sisi yang lainnya. 


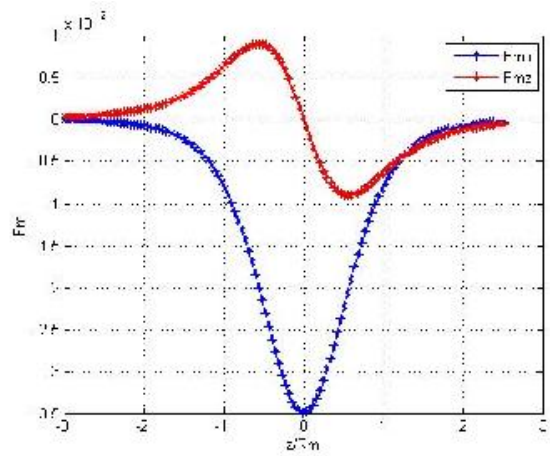

Gambar 9. Komponen gaya magnet $\left(\begin{array}{lll}F & d & F\end{array}\right)$ terhadap sumbu pembuluh darah.

Analisis pada Gambar 9 menunjukan bahwa komponen-komponen pada gaya magnet terhadap pembuluh darahdengan menggunakan (17) dan (18). Hal ini dapat diamatibahwa komponen horizontal dari gaya magnet $(F \quad)$ memiliki bentuk profil yang sama dengan medan magnet dengan arah sebaliknya. Oleh karena itu, $(F \quad)$ berosilasi di sekitar pusat sumbu pembuluh darah dan menunjukkan nilai maksimum terhadap tepi magnet $(z / R= \pm 1)$. Akibatnya,partikel magnetik perjalanan horizontal di atas magnet dari kiri ke kanan itu mengalami percepatan horisontal saat melewati tepi magnet. Namun, mengalami perlambatan setelah selesai melewati tepi magnet. Akibatnya, komponen horizontal gaya magnet $(F \quad)$ bertanggung jawab untuk gerakan osilasi dari nanopartikel dalam pembuluh darah. Selain itu, komponen vertikal gaya magnet $(F \quad)$ adalah terkuat di pusat magnet $(z / R=0)$ dan kekuatannyamenurun seiring menuju tepi magnet $(z / R= \pm 1)$. Nilai dari $F$ $=3,5 p=3,510^{-12} \mathrm{~N}$ di pusat magnet.

\section{Kesimpulan/Ringkasan}

Dari analisis yang telah dilakukan pada lintasan nanopartikel magnet didalam pembuluh darah, maka diperloleh kesimpulan bahwa:

1. Model matematika yang digunakan dalam menentukan lintasan nanopartikel magnet untuk memperoleh hasil yang lebih baik adalah:

$$
\begin{aligned}
& \frac{d}{d}=\mu_{0} \frac{M_{\mathrm{s}}{ }^{2} K_{m}^{4} K_{p}{ }^{2}}{3 \eta}\left(\frac{d}{\left(d^{2}+z^{2}\right)^{3}}\right)-\frac{2 K_{p}{ }^{2}}{9 \eta}\left(\rho_{p}-\rho_{f}\right) g \\
& \frac{d}{d}=\mu_{0} \frac{M_{\mathrm{s}}{ }^{2} K_{m}^{4} K_{p}{ }^{2}}{3 \eta} M_{\mathrm{s}}{ }^{2} R_{m}^{4}\left(\frac{z}{\left(d^{2}+z^{2}\right)^{3}}\right)+2 \overline{V_{J}}\left[1-\left(\frac{x}{K_{v}}\right)^{2}\right]
\end{aligned}
$$

2. Hasil lintasan nanopartikel magnet di dalam pembuluh darah, semakin pendek jarak antara pusat pembuluh darah dengan pusat medan magnet maka semakin banyak partikelpartikel dari nanopartikel magnet yang tertarik oleh medan magnet yang diposisikan diluar tubuh. Sedangkan jarak yang lebih tepat adalah $0.025 \mathrm{~m}$ dari pusat medan magnet.

\section{Daftar Pustaka}

[1] Iswandana, R. Anwar, E. Jufri, M. (2013) "Formulasi Nanopartikel Verapamil Hidroklorida dari Kitosan dan Natrium Tripolifosfat dengan Metode Gelasi Ionik". Universitas Indonesia, Jakarta

[2] Alexiou, C. A. Schmidt, R. Klein, P. Hullin, et al., (2002) "Magnetic drug targeting: biodistribution and dependency on magneticfield strength”, J. Magn. Magn.Mater. 252 (2002) 363-366

[3] Kingsley, J.D.H. Dou, J. Morehead, B. Rabinow, H.E. Gendelman, C.J. Destache, (2006), "Nanotechnology: a focus on nanoparticles as a drug delivery system", J. Neuroimmune Pharma. 1 (2006) 340-350.

[4] Nacev, A.C. Beni, O. Bruno, B. Shapiro, (2011) "The behaviors of ferromagnetic nanoparticles in and around blood vessels under applied magneticfields", J. Magn. Magn.Mater. 323 (2011) 651-668. 
[5] Shaw, S. Murthy, P.V.S.N. Pradhan, S.C. (2010) "Effect ofnon Newtonian characteristics of blood on magnetic targeting in the impermeable microvessel", J. Magn. Magn.Mater. 322 (2010) 1037-1043.

[6] Wahyuni, Nurdin, Juarlin, E. Solution Nanomagnetic Particle Motion in a Fluid Environment Under the Influence of Magnetic Field with Finite Difference Method".University of Hasanuddin,.

[7] Sharma, S. Katiyar, V.K. Singh, U. (2015)" Mathematical modelling for trajectories of magnetic nanoparticles in a blood vessel under magneticfield". Indian Institute of Technology, Roorkee 247667, India.

[8] Martien, R. Adhitamika, Iramie D.K, Iranto, Farida V, Sari D.P, (2012) "Perkembangan Teknologi Nanopartikel sebagai Sistem Penghantaran Obat" Fakultas Farmasi Universitas Gadjah Mada, Minat Studi Rekayasa Biomedis, Sekolah Pascasarjana Universitas Gadjah Mada, Fakultas Farmasi Universitas Ahmad Dahlan,Program Studi Farmasi, Fakultas Kedokteran dan Ilmu Kesehatan Universitas Muhammadiyah Yogyakarta.

[9] Alexiou, C. Ardold, W. Klein, R.J. Parak, F.G. Hulin, P. Bergemann,C. Erhardt, W. Wagenpfeil, S. Lubbe, A.S. (2000). "Locoregional Cancer Treatment with Magnetic Drug Targeting", Technical University of Munich.

[10] Hakim, L., (2008) "Kontrol ukuran dan dispersitas nanopartikel besi oksida". Departemen Kimia, Fakultas MIPA, Universitas Indonesia:Jakarta.

[11] Zagarola, M.V. Smits, A.J. (1996), "Experiments in High Reynolds Number Turbulent Pipe Flow", AIAA paper 96-0654, 34th AIAA Aerospace Sciences Meeting, Reno, Nevada.

[12] Utomo, P. (2010) "Hukum Newton tentang gerak dan gravitasi" departemen Fisika, fakultas FMIPA. Institut Teknologi Sepuluh Nopember: Surabaya.

[13] Zaki, M. (2012) "Medan Elektromagnetik", fakultas FMIPA Institut Teknologi Sepuluh Nopember: Surabaya.

[14] Luknanto, D. (2005) "Mekanika Fluida”. UGM: Jogjakarta.

[15] Fleisch, D, (2008) “A student's Guide to Maxwell's Equations”, Wittenberg University.

[16] Schenck, J.F., (1995) "The role of magnetic susceptibility in magnetic resonance magnetic compatibility of the first and second kinds", general electric corporate research and sevelopment center. New York: Schenectady 12309.

[17] Subakti,I. (2006) “Metode Numerik".Fakultas Teknologi Informasi. Institut Teknologi Sepuluh Nopember: Surabaya. 